\title{
EFEITO DO ÓLEO ESSENCIAL DAS FOLHAS DE Drimys angustifolia EM COLÔNIAS DE Acromyrmex spp. EM PLANTIO DE Pinus taeda
}

\author{
Carlos Meneghetti ${ }^{1}$, Ricardo Andrade Rebelo ${ }^{2}$, Marcelo Diniz Vitorino ${ }^{3 *}$ \\ ${ }^{1}$ Fundação Universidade Regional de Blumenau, Programa de Pós-Graduação em Engenharia Ambiental, Blumenau, Santa Catarina, \\ Brasil - carlosmeneghetti@terra.com.br \\ ${ }^{2}$ Fundação Universidade Regional de Blumenau, Departamento de Química, Blumenau, Santa Catarina, Brasil - ricardorebelo@furb.br \\ ${ }^{3 *}$ Fundação Universidade Regional de Blumenau, Departamento de Engenharia Florestal, Blumenau, Santa Catarina, Brasil - \\ diniz@furb.br
}

Recebido para publicação: 15/07/2014 - Aceito para publicação: 23/06/2015

\begin{abstract}
Formigas causam danos e perdas econômicas em florestas plantadas, principalmente em plantios de Pinus taeda, e no seu controle são utilizados agroquímicos que podem contaminar os processos ecológicos, sendo que a busca por formas alternativas de controle destes insetos nas atividades florestais é prática desejável. Entre as várias formas de controle alternativo existentes, como o manejo do habitat e o controle biológico, há o controle com a utilização de extratos e óleos essenciais obtidos de plantas com propriedades inseticidas. O objetivo principal deste estudo foi avaliar o efeito do óleo essencial extraído das folhas de Drimys angustifolia, em colônias de formigas cortadeiras do gênero Acromyrmex spp., em plantio de $P$. taeda, como alternativa de controle. O óleo essencial foi aplicado em dois tratamentos com concentração de $100 \%$ e $10 \%$ no interior de oito formigueiros ativos com um pulverizador manual e comparado com quatro formigueiros de controle. $\mathrm{O}$ resultado final demonstrou que os oito formigueiros tratados com óleo estavam abandonados, evidenciando a potencial atividade do óleo essencial sobre as formigas, comparado com os formigueiros de controle que se mantiveram ativos. O óleo essencial de D. angustifolia apresentou potencial para ser aplicado como controle alternativo de formigas cortadeiras do gênero Acromyrmex.

Palavras-chave: Formigas cortadeiras; controle alternativo; extração por arraste a vapor; casca-deanta; metabólitos secundários.
\end{abstract}

Resumo

\begin{abstract}
Effect of essential oil from leaves of Drimys angustifolia in colonies of Acromyrmex spp. in pinus taeda planting. Ants cause damage and economic losses in plantation forests, mainly in Pinus taeda; their control implies agrochemicals that can contaminate the ecological processes, and the search for alternative ways to control these insects in the forest activities is a desirable practice. Among the various existing alternative forms of control, such as the habitat management and biological control, there is the control with use of extracts and essential oils of plants with insecticidal properties. The main objective of this research was to evaluate the effect of the essential oil extracted from the leaves of Drimys angustifolia, in colonies of leaf cutting ants of the genus Acromyrmex spp., in planting $P$. taeda, as an alternative control. The essential oil was applied in two treatments with $100 \%$ and $10 \%$ concentrations within eight active nests with a hand sprayer and compared with four nests as control. The final result showed that the eight nests treated with the oil were abandoned, highlighting the potential activity of the essential oil to ants, compared to control nests that remained active. The essential oil of $D$. angustifolia exhibited potential to be applied as alternative control of leaf-cutting ants of the genus Acromyrmex.

Keywords: Leaf cutting ants; alternative control; extraction by steam distillation; bark-of-anta; secondary metabolites.
\end{abstract}

\section{INTRODUÇÃO}

Em sua Política de Químicos, publicada em maio de 2007, o Forest Stewardship Council (FSC), ou Conselho de Manejo Florestal, incluiu na lista de produtos com restrição de uso, alguns muito conhecidos e tradicionalmente utilizados no setor de florestas plantadas para o controle de pragas e doenças, como, por exemplo, a sulfluramida e o fipronil, os dois principais princípios ativos utilizados na forma de iscas 
granuladas, para o controle de formigas cortadeiras. O uso destas substâncias deve ser descontinuado seis meses após a publicação da lista, sob pena de perda da certificação. As empresas florestais brasileiras certificadas entraram com um pedido de derrogação para estes dois princípios ativos, o qual foi aceito pelo FSC e teve a sua inclusão na lista de aprovação das derrogações dos inseticidas altamente perigosos em 28 de abril de 2010, com vencimento em 28 de abril de 2015 (FSC, 2012; LOPES, 2012).

As derrogações normalmente são emitidas para um período de cinco anos, não sendo permitida extensão da derrogação depois do vencimento deste prazo. Portanto, as empresas florestais brasileiras, que são certificadas pelo FSC, terão que abandonar ou diminuir drasticamente o uso da sulfluramida e do fipronil e encontrar soluções e produtos alternativos para o controle de formigas cortadeiras, substituindo estes dois princípios ativos por outros, que não sejam prejudiciais ao meio ambiente, para que não percam as suas certificações deste que é um importante selo verde do mundo (LOPES, 2012).

Entre as formigas que causam maiores danos estão as do gênero Acromyrmex Mayr, 1865, conhecidas como quem-quens. Esta situação se deve ao controle sistemático dado às formigas do gênero Atta Fabricius, 1805, denominadas de saúvas, e que têm métodos de controle mais definidos e eficientes; menor número de espécies do gênero Atta de importância florestal, o que propiciou maiores estudos; e aos ninhos de Atta serem mais evidentes (PEREIRA, 2007; PACHECO; BERTI FILHO, 1987 apud UKAN, 2008). Em algumas regiões, principalmente no sul do Brasil, as quem-quens podem ter maior importância econômica na agropecuária e atividades florestais do que as saúvas (JACCOUD, 2000). Em virtude da importância econômica para o Brasil, as principais pesquisas e publicações sobre formigas cortadeiras estão concentradas na tribo Attini (Hymenoptera: Formicidae), principalmente nos gêneros Atta e Acromyrmex. Além disso, em Acromyrmex são escassos os estudos quando comparados à quantidade dos realizados com Atta, e muito do que se tem sobre Acromyrmex (principalmente em relação a comportamento, hábitos, danos causados e controle) é baseado e adaptado de estudos sobre Atta.

As formigas cortadeiras podem causar a desfolha total, tanto de mudas como de plantas adultas. No entanto, a idade das plantas pode influenciar na vulnerabilidade da floresta aos prejuízos causados por formigas. Os danos são maiores em mudas recém-plantadas e em plantas jovens, sendo que na fase inicial do plantio, as perdas por esses insetos podem ser irreversíveis, pela fragilidade das mudas (CHERRETT, 1986; DELLA LUCIA, 2011; HÖLLDOBLER; WILSON, 1990; VASCONCELOS; CHERRET, 1997).

$\mathrm{O}$ controle químico é a forma mais utilizada atualmente no controle às formigas cortadeiras. $\mathrm{O}$ emprego de iscas granuladas, principalmente através de macro porta-iscas e micro porta-iscas, é considerado o método mais eficiente, prático e econômico de controle de formigas cortadeiras. As iscas granuladas oferecem maior segurança ao operador, dispensam mão de obra e equipamentos especializados e permitem o tratamento de formigueiros em locais de difícil acesso (BOARETTO; FORTI, 1997; PEREIRA, 2007; SOUSA, 1996; UKAN, 2008; ZANETTI et al., 2002).

A necessidade de métodos mais seguros no controle de insetos tem estimulado a busca de novos inseticidas em plantas, visando diminuir a utilização de produtos sintéticos, que praticamente acabaram por substituir completamente os inseticidas naturais. Por serem mais potentes que os produtos naturais, que foram muito utilizados até a década de 1940, os produtos sintéticos foram utilizados indiscriminadamente durante muitas décadas, acarretando em sérios prejuízos à saúde humana em virtude da sua acumulação e alta persistência no meio ambiente (VIEIRA et al., 2010), causando danos ecológicos e poluição do meio ambiente (MARICONI, 1981).

Um dos objetivos dos estudos com as plantas que apresentam potencial inseticida é a obtenção de derivados vegetais naturais para uso direto no controle de pragas. A descoberta de novos compostos aumenta a diversidade de moléculas empregadas no controle às pragas, diminuindo, consequentemente, a probabilidade de ocorrer acúmulo no ambiente e de provocar resistência nos insetos (BUENO, 2005).

A presença de óleos essenciais nos vegetais é bastante frequente, sendo inúmeras as propriedades farmacológicas que são atribuídas a estes metabólitos secundários, notadamente suas ações antibacterianas e fungicidas, já comprovadas cientificamente através de diversos estudos, além de sua função de proteção contra a herbivoria.

Estudos realizados, com ensaios preliminares in vitro, têm demonstrado que o óleo essencial presente nas folhas e cascas de Drimys angustifolia Miers, 1858 (Canellales: Winteraceae), conhecida popularmente como casca de anta ou cataia, tem apresentado atividades antifúngica (MALHEIROS, 2001) e antibacteriana (MENEGHETTI, 2010) quando utilizado com fins medicinais e terapêuticos. Em estudos recentes com os constituintes isolados do óleo essencial de outras espécies vegetais, também presentes no óleo essencial de $D$. angustifolia, entre eles drimenol, biciclogermacreno, miristicina e 
ciclocolorenona, foram obtidos resultados positivos em relação à ação inseticida, larvicida, antibacteriana e antifúngica destes constituintes isoladamente pesquisados (SILVA et al., 2007; RIBEIRO et al., 2008; DERITA et al., 2009; FLORIANI, 2010; GAVIRIA et al., 2011).

Conforme verificado pelo autor do presente estudo em observações de campo, as folhas de $D$. angustifolia sofrem poucos ataques de herbivoria por insetos. Portanto, é possível presumir que, apesar da atratividade das folhas aos insetos, estas possuem algum constituinte, ou mistura de constituintes, em seu óleo essencial que provoque antagonismo, impedindo a continuidade do processo de herbivoria. Este estudo apresenta como hipótese a comprovação do efeito deletério do óleo essencial das folhas de $D$. angustifolia em colônias de formigas do gênero Acromyrmex spp.

Os objetivos deste estudo foram avaliar o efeito da aplicação a campo de diferentes concentrações do óleo essencial das folhas de $D$. angustifolia (obtido através de extração por arraste a vapor) em colônias de formigas do gênero Acromyrmex spp. em plantios de Pinus taeda Linnaeus, 1758; verificar a influência das diferentes concentrações no forrageamento e se a temperatura interna da colônia é um parâmetro adequado para a avaliação do efeito do óleo de $D$. angustifolia nas colônias a campo.

\section{MATERIAL E MÉTODOS}

A parte experimental deste estudo dividiu-se em duas etapas distintas. A primeira etapa correspondeu à coleta das folhas de $D$. angustifolia, extração do óleo essencial e a sua caracterização química. A segunda etapa referiu-se à realização do experimento em campo, com a definição da escolha do local, seleção dos formigueiros, aplicação do óleo essencial nos formigueiros e aquisição dos dados.

As folhas de D. angustifolia foram coletadas no Morro da Igreja, localizado no Parque Nacional de São Joaquim, no município de Urubici, estado de Santa Catarina. As autorizações de coleta foram registradas no Sistema de Autorização e Informação em Biodiversidade (SISBIO) sob os números 297081, 29708-2 e 29612-1. Alguns dos indivíduos coletados estavam férteis, com flores ou frutos. Amostras do material vegetal fértil foram encaminhadas para o herbário Dr. Roberto Miguel Klein, localizado na Universidade Regional de Blumenau (FURB). A exsicata foi depositada no herbário sob o número 37235.

Foi realizado o acompanhamento da perda de massa das folhas da primeira coleta, para fins de determinação da quantidade total de folhas a serem coletadas, tendo em vista o rendimento de óleo extraído e a obtenção da quantidade necessária para a aplicação do experimento em campo.

O óleo essencial foi obtido das folhas através de extração por arraste a vapor em equipamento industrial, com dorna de capacidade volumétrica de 300 litros. O procedimento para extração do óleo essencial não segue protocolo pré-determinado em relação ao tempo de extração e em relação ao calor necessário para produção do vapor. A água utilizada na caldeira deste equipamento para geração de vapor foi proveniente da captação da chuva, não sofrendo nenhum tratamento químico, apenas filtração para eliminação de eventuais corpos estranhos. Após a extração, o óleo essencial foi filtrado em filtro de papel com sílica granulada para remover qualquer resíduo de água presente, obtendo-se assim um óleo essencial sem contato com qualquer tipo de solvente.

A caracterização química dos constituintes do óleo essencial foi realizada em amostras encaminhadas para análise por cromatografia gasosa com detector de ionização de chama (CG-DIC) no Laboratório de Síntese e Tecnologia (SINETEC) do Departamento de Química do campus I da FURB e por cromatografia gasosa acoplada à espectrometria de massas (CG-EM) no Laboratório de Cromatografia do campus II da FURB.

A segunda etapa do experimento foi conduzida em talhões de $P$. taeda de uma unidade florestal da empresa Celulose Irani S/A, no município de Vargem Bonita, estado de Santa Catarina, na Fazenda Campina da Alegria. Os talhões sofreram colheita em maio e subsolagem em julho de 2012. As mudas de P. taeda foram plantadas em setembro de 2012 e estavam com 15 a $25 \mathrm{~cm}$ de altura, aproximadamente, quando o experimento teve início.

A aplicação do experimento em campo teve início em 24/11/2012 e foi finalizada em 12/01/2013, com a última visita realizada para coleta de dados dos formigueiros. Nesta última visita todos os formigueiros dos três tratamentos foram totalmente abertos, para verificar se havia atividade ou não e se havia a presença ou não de formigas e fungo.

As colônias que apresentaram forrageamento tiveram um ponto fixo marcado no carreiro de forrageamento, o mais próximo possível do ninho, para a contagem de formigas que forrageavam material verde durante 5 minutos antes da aplicação e durante 5 minutos após a aplicação dos tratamentos. As

FLORESTA, Curitiba, PR, v. 45, n. 4, p. 755 - 768 , out. / dez. 2015. 
colônias que apresentaram forrageamento nos dias seguintes ao da aplicação do tratamento, também tiveram o forrageamento contado durante 5 minutos nos seus respectivos pontos de monitoramento quando esta atividade estava ocorrendo nos dias de inspeção.

Foram selecionadas doze colônias de formigas do gênero Acromyrmex (Hymenoptera: Formicidae), espécies A. crassispinus Forel, 1909 e A. hispidus Santschi, 1925, adotando como critérios a sua área máxima, que deveria ser inferior a $1 \mathrm{~m}^{2}$, tendo em vista alcançar um padrão de uniformização, e a existência de atividade no ninho, determinada através da avaliação de forrageamento ou da verificação da atividade interna na colônia.

De cada formigueiro foram coletados indivíduos para identificação das espécies, que foi realizada pela Dra. Mariane Aparecida Nickele. As amostras identificadas foram depositadas na coleção do Laboratório de Monitoramento e Proteção Florestal (LAMPF) do Departamento de Engenharia Florestal da FURB, localizado no campus II.

Os formigueiros de A. crassispinus receberam as denominações de F02, F09, F11, F13, F21, F22, F23 e F30. Os formigueiros de A. hispidus receberam as denominações de F14, F27, F31 e F32.

A aplicação do experimento em campo foi realizada em três tratamentos, denominados de "Tratamento I", com concentração de óleo de 100\%; "Tratamento II", com concentração de óleo de 10\%; e "Tratamento III (Controle)", sem aplicação, servindo de testemunhas. Foram padronizadas apenas duas concentrações devido à dificuldade de obtenção do óleo de $D$. angustifolia.

No Tratamento I, o óleo essencial das folhas de $D$. angustifolia foi aplicado em quatro formigueiros (F02, F13, F23 e F30) que receberam uma aplicação de $200 \mathrm{~mL}$ de óleo cada, em dose única.

No Tratamento II, quatro formigueiros (F14, F21, F22 e F27) receberam uma aplicação de $20 \mathrm{~mL}$ de óleo diluídos em $180 \mathrm{~mL}$ de água destilada cada, em dose única. As diluições deste tratamento foram agitadas vigorosamente por 30 segundos aproximadamente, antes da aplicação nos formigueiros, para que ocorresse a composição uniforme da mistura de óleo e água, formando um líquido de aparência esbranquiçada, indicando a sua emulsificação.

No Tratamento III (Controle) foram utilizados quatro formigueiros (F09, F11, F31 e F32) que não receberam nenhuma aplicação.

As aplicações nos formigueiros do Tratamento I e nos formigueiros do Tratamento II foram realizadas com um pulverizador de pressurização manual, novo e em perfeitas condições de uso, com capacidade para $5 \mathrm{~L}$.

Todas as aplicações nos oito formigueiros (Tratamentos I e II) foram realizadas em dose única, introduzindo o bico do pulverizador no topo do formigueiro buscando a panela de fungo, girando suavemente a haste de pulverização $360^{\circ}$, lenta e continuamente, tantas vezes quanto o necessário até o esgotamento do líquido no reservatório do pulverizador.

A primeira aplicação efetuada foi o Tratamento I (100\%) em 29/11/2012 em três formigueiros, sendo que o quarto formigueiro deste tratamento recebeu a aplicação no dia 01/12/2012. A segunda aplicação efetuada foi o Tratamento II (10\%) em 08/12/2012 para os quatro formigueiros deste tratamento.

Para a obtenção dos dados foram realizadas uma ou duas visitas diárias de inspeção nos formigueiros nos primeiros 15 dias após a aplicação dos tratamentos, acrescidas de mais uma visita no trigésimo dia e uma visita no quadragésimo quinto dia após a aplicação dos tratamentos, sendo que os formigueiros utilizados como testemunhas também seguiram esta previsão de visitas. O intervalo de horas entre a primeira e a segunda visita diária (quando esta ocorreu) não seguiu um cronograma fixo, tendo sido realizada uma visita de inspeção matutina e outra vespertina. Foram anotados a temperatura interna do formigueiro, a temperatura externa do ambiente e a umidade relativa do ar externa do ambiente. $\mathrm{O}$ equipamento utilizado para a obtenção destes dados foi um termohigrômetro digital novo, modelo AK28, e comprimento da sonda do sensor externo de $3 \mathrm{~m}$, a qual foi introduzida no interior do formigueiro com o auxílio de uma haste de madeira.

Em todas as visitas de inspeção foi verificada a presença ou ausência de atividade nos formigueiros. O critério adotado para considerar o abandono do formigueiro foi a ausência de formigas após estímulos produzidos no ninho com o auxílio da haste de madeira utilizada para introduzir a sonda de temperatura externa do termohigrômetro.

As temperaturas interna e externa do formigueiro, assim como a umidade relativa do ar, foram tomadas em cada visita realizada 10 minutos após a instalação do equipamento no formigueiro. A sonda para verificação da temperatura interna do formigueiro foi introduzida na panela de fungo através do orifício formado no local da aplicação, sendo o equipamento instalado sobre o formigueiro. 
Em cada visita de inspeção realizada nos formigueiros que receberam os tratamentos e nos formigueiros de controle, além da temperatura interna do formigueiro, temperatura externa e umidade relativa do ar, foram anotadas a data e hora da visita, condições climáticas (sol, nuvens, chuva), atividade no formigueiro, observações gerais, dados específicos, como espécie, localização, tamanho e tratamento aplicado e se havia forrageamento ou não. Nos casos em que havia forrageamento, foi anotada a quantidade de formigas carregando material vegetal verde que passavam em determinado ponto do carreiro durante 5 minutos. Após a aplicação dos tratamentos todos os formigueiros foram inspecionados no mesmo dia, não havendo um número pré-fixado de visitas para cada formigueiro.

Os dados obtidos foram analisados primeiramente para determinação de sua normalidade e a seguir, se paramétricos, submetidos à análise de variância e, se não paramétricos, submetidos ao teste de Kruskal-Wallis. Nos casos em que houve significância foi aplicado o teste de Tukey ao nível de 5\% de probabilidade para os dados paramétricos e o teste U de Mann-Whitney para os dados não paramétricos.

\section{RESULTADOS E DISCUSSÃO}

Os resultados qualitativos e quantitativos da parte experimental desta pesquisa foram analisados estatisticamente e fornecem subsídios para a etapa de discussão, a qual foi realizada com base nos dados da observação de campo e de literatura específica.

As coletas de folhas de D. angustifolia renderam $393,00 \mathrm{~kg}$ de folhas frescas, que representaram $152,52 \mathrm{~kg}$ de folhas secas, entre material pesado e calculado, conforme representado na tabela 1 (A).

O volume total de óleo extraído das quatro coletas foi de $920 \mathrm{~mL}$, representando $0,21 \%$ em relação ao material fresco e $0,55 \%$ em relação ao material seco, conforme tabela 1(B).

Tabela 1. Coletas realizadas em $\mathrm{kg}$ (A) e rendimentos obtidos em \% (B).

Table 1. Collections made in $\mathrm{kg}(\mathrm{A})$ and yields obtained in \% (B).

\begin{tabular}{|c|c|c|c|c|c|}
\hline \multirow{2}{*}{ Data coleta } & \multicolumn{2}{|c|}{ (A) Material (Kg) } & \multicolumn{3}{|c|}{ (B) Rendimentos (\%) } \\
\hline & Fresco & Seco & $\mathbf{m L}$ & Fresco & Seco \\
\hline Jan e fev/2012 & $47,00 \mathrm{a}$ & $18,24 \mathrm{~b}$ & 100 & 0,19 & 0,50 \\
\hline Março/2012 & $145,00 \mathrm{~b}$ & 56,27 a & 320 & 0,20 & 0,52 \\
\hline Setembro/2012 & $201,00 \mathrm{~b}$ & $78,01 \mathrm{a}$ & 500 & 0,23 & 0,59 \\
\hline Totais & 393,00 & 152,52 & 920 & 0,21 & 0,55 \\
\hline
\end{tabular}

a: calculado; b: pesado

Em experimento realizado por Limberger et al. (2007) o rendimento de óleo extraído em laboratório foi de $0,4 \%$ para folhas frescas e de $0,3 \%$ para cascas do caule para esta espécie coletada em novembro de 2001 no município de São Francisco de Paula, no Rio Grande do Sul.

No entanto, o presente trabalho obteve um rendimento inferior, porém compatível com o esperado para uma extração em escala industrial, uma vez que os rendimentos em laboratório geralmente são superiores devido aos fatores de controle não serem influenciados pelo ambiente, tais como temperatura da dorna, escala de produção, pressão de trabalho, entre outros.

A caracterização química do óleo, realizada em amostras obtidas de duas coletas, apresentou os valores percentuais médios, entre os constituintes majoritários, obtidos através do cálculo da análise do tempo de retenção (ADAMS, 2007), conforme apresentado na figura 1. Limberger et al. (2007), no mesmo experimento citado anteriormente, obtiveram rendimentos diferentes para os mesmos constituintes, obtidos da extração do óleo das folhas frescas de $D$. angustifolia, conforme apresentado na figura 1.

Esta variação no percentual dos constituintes pode ser devido a diversos fatores, entre eles a sazonalidade, temperatura, localização, condições edafoclimáticas, poluição, estresse hídrico e herbivoria, entre outros (GOBBO-NETO; LOPES, 2007; PIZZAMIGLIO, 1991).

Alguns destes constituintes presentes no óleo das folhas de D. angustifolia, entre eles $\alpha$-pipeno; $\beta$-pipeno e limoneno, são os mesmos presentes em acículas maduras de $P$. taeda que não foram atacadas por formigas, conforme observado por Cantarelli et al. (2003), não sendo verificados esses compostos secundários em acículas jovens atacadas.

Uma possível explicação para este fato pode ser a influência destes constituintes na

FLORESTA, Curitiba, PR, v. 45, n. 4, p. 755 - 768 , out. / dez. 2015. 
palatabilidade das acículas pelas formigas, podendo-se inferir que a presença destes constituintes em algum produto possa ter propriedades repelentes às formigas.

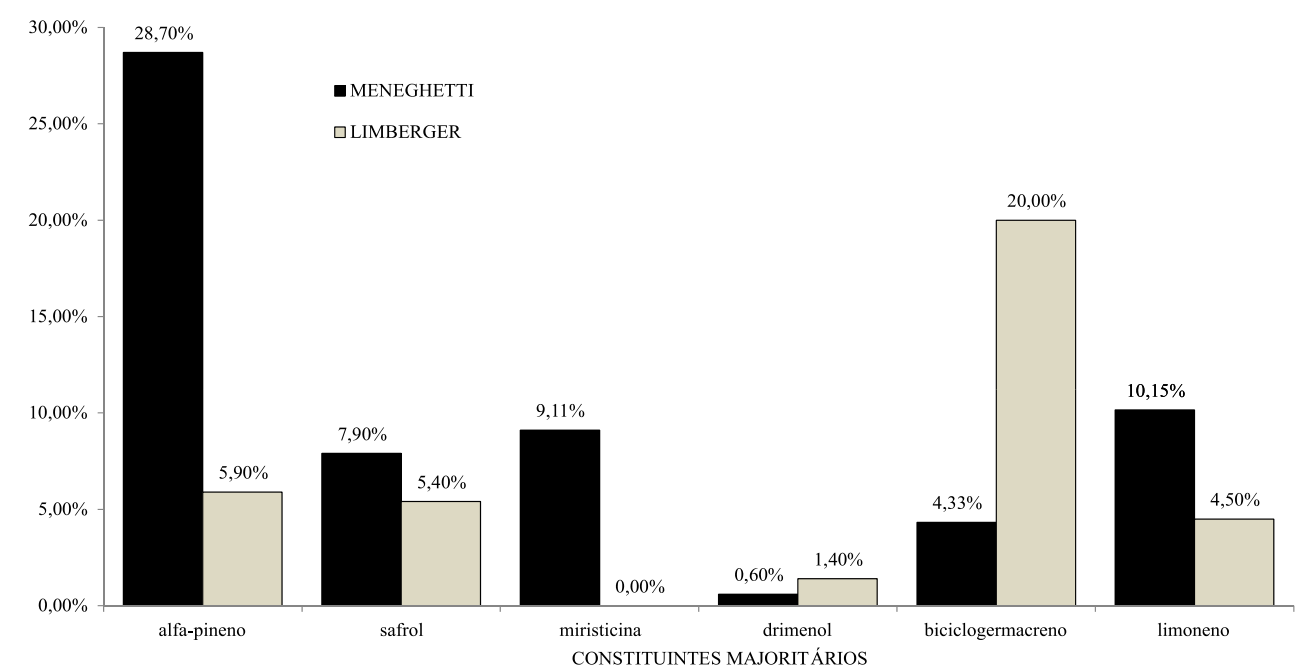

Figura 1. Constituintes majoritários do óleo essencial de D. angustifolia

Figure 1. Major constituents of the essential oil of D. angustifolia

Das 12 colônias selecionadas para os três tratamentos apenas quatro apresentaram forrageamento, sendo que as primeiras foram a F23, F13 e F02, no quinto dia; e F30, no sétimo dia; todas estas do Tratamento I. As demais colônias do Tratamento II (F14, F21, F22 e F27) e do Tratamento III (F09, F11, F31 e F32) não apresentaram forrageamento.

Nas quatro colônias do Tratamento I que apresentaram forrageamento, as distâncias dos pontos de monitoramento do forrageamento nos carreiros até os ninhos foram de 4,0 m para F23; 1,0 m para F13; 1,2 m para F02 e 1,6 m para F30.

Na última visita de inspeção, ao final do experimento, os formigueiros do Tratamento I (100\%) e do Tratamento II (10\%) foram abertos para comprovar o abandono. Todos os formigueiros dos dois tratamentos apresentavam-se sem formigas e sem fungo, com exceção de um formigueiro (F27) do Tratamento II (10\%), que apresentava indícios de restos de fungo esporulado.

Os quatro formigueiros do Tratamento I (100\%) e os quatro formigueiros do Tratamento II (10\%) estavam extintos após determinado intervalo de dias de suas respectivas aplicações, conforme apresentado na figura 2 .

Os formigueiros do Tratamento III (Controle) não apresentaram abandono das colônias durante o período de duração do experimento, apresentando formigas e fungo, além de sua estrutura externa perfeita e em bom estado de conservação. Estes também foram abertos na última visita e em três deles foi constatada a atividade da colônia, com a presença de formigas e de fungo. O quarto formigueiro (F32) não apresentou formigas nem fungo, porém o mesmo apresentava a sua estrutura externa perfeita e em bom estado de conservação.

Uma possível explicação para este fato pode ser devido à migração de colônias de $A$. crassispinus ser muito comum, conforme foi observado em estudos realizados por Nickele (2013), onde é apontado que uma colônia de formigas cortadeiras pode migrar após sofrer algum tipo de perturbação, como a intoxicação com iscas formicidas, enchentes, escassez de recursos para o forrageamento e interações competitivas intra e interespecíficas.

Outra possível explicação para a ausência de formigas no formigueiro F32 poderia ser devido à revoada, conforme verificado por Nickele (2013) em seu estudo, porém o tamanho deste formigueiro $\left(0,182 \mathrm{~m}^{2}\right)$ não é compatível com este comportamento, não sendo possível, portanto, confirmar qual destes fatores contribuiu para o abandono da colônia.

A morte do formigueiro F32 é pouco provável, já que rainhas de Acromyrmex podem viver por até 10 anos em condições de laboratório, conforme observado por Weber (1972). Além disso, os ninhos 
de quem-quem são semi-claustrais, ou seja, a rainha sai para forragear na tentativa de garantir uma melhor formação do jardim de fungo, apesar do perigo de predação (FERNANDÉZ-MARÍN et al., 2004). As operárias de Acromyrmex raramente põem ovos na presença da rainha, mas em colônias órfãs as operárias se reproduzem quando a rainha morre ou fica ausente da colônia (CAMARGO et al., 2006).

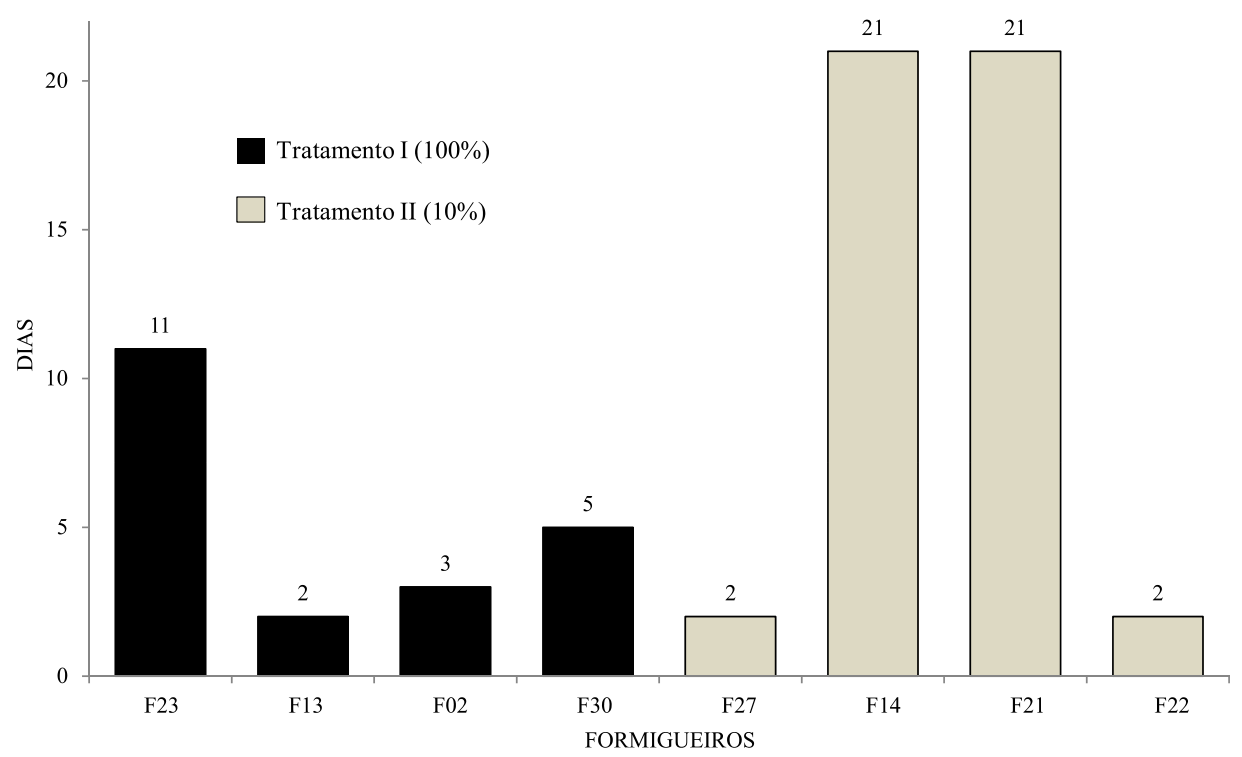

Figura 2. Número de dias da ocorrência de abandono após os tratamentos.

Figure 2. Number of days of the occurrence of abandonment after treatments.

A observação da atividade das formigas após a aplicação dos Tratamentos I e II demonstra que a aplicação do óleo no Tratamento I causou um efeito imediato e visível, tanto sobre o forrageamento quanto no comportamento de fuga ou mudança para um novo local. As principais alterações de comportamento observadas após a aplicação do Tratamento I foram o transporte para fora do formigueiro de fungo, material seco e ovos, além de atividades intensas no carreiro sem transporte de material (tabela 2). Como no Tratamento I a aplicação foi de óleo puro (concentração de 100\%), observou-se comportamento anormal nas colônias, conforme apresentado na tabela 2.

No Tratamento II não foi observado tal comportamento sobre o forrageamento uma vez que todos estes formigueiros não apresentaram esta atividade durante a duração do experimento. Também não foi observado comportamento de fuga ou mudança para novo local neste tratamento. Possíveis causas para esta ausência de comportamento de fuga podem ser devido à concentração da diluição (10\%), tornando o seu efeito mais lento e ao intervalo de 18 dias entre duas observações durante o período do experimento, comportamento este que pode ter ocorrido e não foi observado neste intervalo.

Não foi possível avaliar estatisticamente o forrageamento nos formigueiros dos Tratamentos II e III por não apresentarem esta atividade durante os 49 dias de duração do experimento, o que fez com que o critério para avaliação estatística dos mesmos, assim como do Tratamento I, fosse apenas a avaliação da temperatura interna, conforme literatura baseada em Powel e Stradling (1986) e Bollazzi e Roces (2010).

Uma provável causa para a ausência de forrageamento na maioria dos formigueiros selecionados pode ser devido à baixa umidade relativa do ar, oscilando entre $10 \%$ a $44 \%$, com média de $37 \%$, em observações realizadas nos dias que antecederam a efetiva aplicação dos tratamentos. Esta ausência de forrageamento quando da ocorrência de baixas taxas de umidade relativa do ar foi constatada por Nickele (2013), em estudo onde foi verificado que A. crassispinus não forrageou em temperaturas abaixo de 10$11{ }^{\circ} \mathrm{C}$ e umidade relativa do ar abaixo de $40 \%$, indicando que flutuações de temperatura e de umidade podem provocar alterações na taxa de respiração das formigas e na perda de água, bem como afetar o equilíbrio hídrico das plantas que foram cortadas, o que pode afetar indiretamente o tempo de manipulação e a qualidade nutricional das plantas que servirão de substrato ao fungo simbionte.

FLORESTA, Curitiba, PR, v. 45, n. 4, p. 755 - 768 , out. / dez. 2015.

Meneghetti, C. et al.

ISSN eletrônico 1982-4688 / ISSN impresso 0015-3826

DOI: $10.5380 /$ rf.v45i4.37111 
Tabela 2. Comportamentos de forrageamento e de fuga/mudança - Tratamento I (100\%).

Table 2. Foraging behavior and escape/change - Treatment I (100\%).

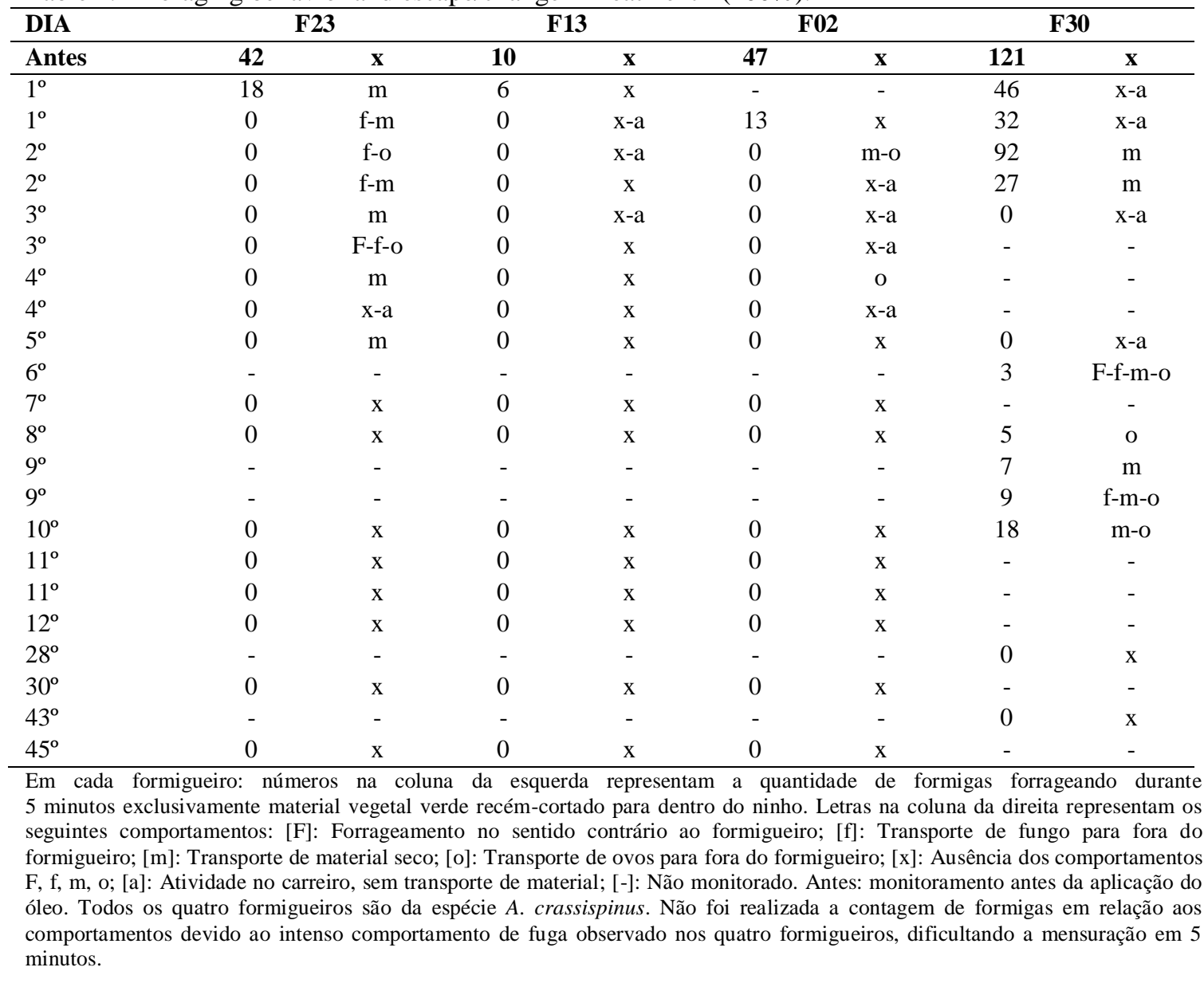

O presente estudo procurou demonstrar, conforme um dos seus objetivos específicos, a relação entre a temperatura interna do formigueiro e a viabilidade do mesmo, o que não foi comprovado pelos dados das temperaturas coletadas e as avaliações estatísticas realizadas quando confrontado com os dados de Powel e Stradling (1986) e Bollazzi e Roces (2010). Os resultados da avaliação estatística apontaram, neste caso específico, que não houve diferença significativa entre os dois tratamentos com aplicação do óleo e o tratamento de controle.

As temperaturas externas e internas anotadas nas observações de campo para os três tratamentos estão apresentadas nas tabelas 3, 4 e 5.

É possível observar, da análise das temperaturas internas dos Tratamentos I e II, que esta permaneceu superior a $20^{\circ} \mathrm{C}$ e inferior a $30^{\circ} \mathrm{C}$, com média geral em torno de $23{ }^{\circ} \mathrm{C}$, na maior parte do tempo de duração do experimento, caindo para valores inferiores ou próximos a $20^{\circ} \mathrm{C}$ nos dias finais do experimento, quando comprovadamente não havia mais formigas nas colônias, independente das variações ocorridas na temperatura externa.

Foi realizada a avaliação estatística dos dados da temperatura interna de todos os formigueiros em todos os tratamentos para determinar se havia diferença significativa entre os tratamentos, sendo constatado que não houve diferença significativa entre os mesmos.

Baseado nos estudos de Powel e Stradling (1986) e Bollazzi e Roces (2010), foi adotado como um dos critérios de abandono do formigueiro a constatação da temperatura interna inferior a $20^{\circ} \mathrm{C}$ nos levantamentos estatísticos realizados. De acordo com os dois estudos, o fungo simbionte cultivado pelas formigas cortadeiras, que representa a única fonte de alimento para as larvas em desenvolvimento, requer 
alta umidade e temperaturas entre $20^{\circ} \mathrm{C}$ e $25^{\circ} \mathrm{C}$ para o seu desenvolvimento adequado, sendo que temperaturas superiores a $30^{\circ} \mathrm{C}$ são letais para o fungo. Os autores constataram, ainda, que as formigas também realizam a termorregulação da colônia, sendo que no presente estudo de campo também foi possível constatar indícios de termorregulação.

Tabela 3. Temperaturas internas e externas $\left({ }^{\circ} \mathrm{C}\right)$ observadas no Tratamento I $(100 \%)$.

Table 3. Internal and external temperatures $\left({ }^{\circ} \mathrm{C}\right)$ observed in Treatment I $(100 \%)$.

\begin{tabular}{|c|c|c|c|c|c|c|c|c|}
\hline \multirow{2}{*}{$\begin{array}{l}\text { Formigueiro } \\
\text { Data }\end{array}$} & \multicolumn{2}{|c|}{ F23 (CR) } & \multicolumn{2}{|c|}{ F13 (CR) } & \multicolumn{2}{|c|}{ F02 (CR) } & \multicolumn{2}{|c|}{ F30 (CR) } \\
\hline & Externa & Interna & Externa & Interna & Externa & Interna & Externa & Interna \\
\hline $29 / 11 / 2012$ & 22,9 & 23,1 & 25,5 & 21,8 & & & & \\
\hline $29 / 11 / 2012$ & 32,7 & 25,8 & 33,3 & 23,9 & 30,4 & 21,5 & & \\
\hline $30 / 11 / 2012$ & 23,1 & 20,5 & 23,1 & 20,8 & 26,2 & 21,3 & & \\
\hline $30 / 11 / 2012$ & 33,3 & 23,5 & 30,1 & 22,9 & 32,4 & 21,7 & & \\
\hline $01 / 12 / 2012$ & 23,5 & 19,7 & 28,9 & 20,5 & 31,9 & 19,4 & 31,5 & 26,9 \\
\hline $01 / 12 / 2012$ & 46,1 & 26,6 & 39,7 & 23,9 & 38,9 & 22,5 & 35,0 & 28,9 \\
\hline $02 / 12 / 2012$ & 27,9 & 20,6 & 32,8 & 21,3 & 29,2 & 21,4 & 29,2 & 29,0 \\
\hline $02 / 12 / 2012$ & 28,7 & 26,8 & 26,1 & 23,1 & 24,4 & 23,1 & 24,6 & 28,9 \\
\hline $03 / 12 / 2012$ & 24,4 & 23,9 & 27,6 & 21,0 & 34,8 & 22,5 & 32,3 & 28,0 \\
\hline $05 / 12 / 2012$ & 33,1 & 28,0 & 30,9 & 25,8 & 28,5 & 25,5 & 24,7 & 29,2 \\
\hline $06 / 12 / 2012$ & 24,1 & 22,9 & 25,2 & 22,2 & 27,2 & 23,1 & 29,7 & 28,8 \\
\hline $08 / 12 / 2012$ & 34,3 & 26,7 & 39,3 & 23,8 & 36,6 & 25,2 & 30,4 & 28,5 \\
\hline $09 / 12 / 2012$ & 24,6 & 23,5 & 34,0 & 28,7 & 33,3 & 24,4 & 29,2 & 28,8 \\
\hline $09 / 12 / 2012$ & 35,1 & 26,4 & 36,5 & 25,8 & 31,7 & 25,8 & 27,7 & 28,5 \\
\hline $10 / 12 / 2012$ & 23,9 & 20,0 & 31,7 & 28,8 & 31,5 & 22,5 & 29,9 & 28,6 \\
\hline $28 / 12 / 2012$ & 23,1 & 18,1 & 22,8 & 20,7 & 25,1 & 18,8 & 30,4 & 26,3 \\
\hline $12 / 01 / 2013$ & 32,0 & 17,8 & 44,2 & 20,0 & 47,6 & 18,4 & 51,0 & 25,1 \\
\hline Média geral & 28,988 & 23,171 & 31,276 & 23,235 & 31,856 & 22,319 & 31,200 & 28,115 \\
\hline Média com form. & & 24,008 & & 22,850 & & 21,500 & & 28,340 \\
\hline Média sem form. & & 21,160 & & 23,287 & & 22,508 & & 27,975 \\
\hline
\end{tabular}

Temperaturas internas "sem negrito e sem fundo cinza": presença de formigas; temperaturas internas "em negrito e com fundo cinza": ausência de formigas. (CR): A. crassispinus.

Tabela 4. Temperaturas internas e externas $\left({ }^{\circ} \mathrm{C}\right)$ observadas no Tratamento II $(10 \%)$.

Table 4. Internal and external temperatures $\left({ }^{\circ} \mathrm{C}\right)$ observed in Treatment II (10\%).

\begin{tabular}{|c|c|c|c|c|c|c|c|c|}
\hline \multirow{2}{*}{$\begin{array}{l}\text { Formigueiro } \\
\text { Data }\end{array}$} & \multicolumn{2}{|c|}{ F27 (HI) } & \multicolumn{2}{|c|}{ F14 $(\mathrm{HI})$} & \multicolumn{2}{|c|}{ F21 (CR) } & \multicolumn{2}{|c|}{ F22 (CR) } \\
\hline & Externa & Interna & Externa & Interna & Externa & Interna & Externa & Interna \\
\hline $08 / 12 / 2012$ & 32,6 & 28,5 & 40,2 & 29,9 & 36,3 & 25,1 & 35,7 & 22,9 \\
\hline 09/12/2012 & 28,5 & 25,5 & 38,8 & 25,3 & 36,4 & 23,3 & 36,1 & 22,4 \\
\hline 09/12/2012 & 38,0 & 25,5 & 35,1 & 25,9 & 31,6 & 25,6 & 29,5 & 25,6 \\
\hline $10 / 12 / 2012$ & 28,5 & 24,1 & 33,6 & 26,0 & 41,3 & 21,6 & 42,5 & 21,9 \\
\hline $28 / 12 / 2012$ & 25,1 & 20,7 & 27,5 & 22,4 & 22,0 & 19,2 & 22,9 & 19,3 \\
\hline $12 / 01 / 2013$ & 37,5 & 22,0 & 43,8 & 23,2 & 48,0 & 19,8 & 40,5 & 19,0 \\
\hline Média Geral & 31,700 & 24,383 & 36,500 & 25,450 & 35,933 & 22,433 & 34,533 & 21,850 \\
\hline Média com form. & & 27,000 & & 26,775 & & 23,900 & & 22,650 \\
\hline Média sem form. & & 23,075 & & 22,800 & & 19,500 & & 21,450 \\
\hline
\end{tabular}

Temperaturas internas "sem negrito e sem fundo cinza": presença de formigas; temperaturas internas "em negrito e com fundo cinza": ausência de formigas. (CR): A. crassispinus. (HI): A. hispidus.

Embora os resultados observados em campo não puderam ser confirmados através das análises estatísticas, o resultado das colônias tratadas com o óleo essencial de $D$. angustifolia foi o abandono das mesmas nos dois tratamentos realizados. Devido à análise estatística ter sido realizada com os dados da

FLORESTA, Curitiba, PR, v. 45, n. 4, p. 755 - 768 , out. / dez. 2015.

Meneghetti, C. et al.

ISSN eletrônico 1982-4688 / ISSN impresso 0015-3826

DOI: $10.5380 /$ rf.v45i4.37111 
temperatura interna dos formigueiros, pode-se concluir que o critério adotado para a escolha dos parâmetros de verificação estatística (temperatura interna) não foi ideal para demonstrar a ação do óleo sobre os formigueiros, conforme comprovado pela observação de campo.

Tabela 5. Temperaturas internas e externas $\left({ }^{\circ} \mathrm{C}\right)$ observadas no Tratamento III (Controle).

Table 5. Internal and external temperatures $\left({ }^{\circ} \mathrm{C}\right)$ observed in Treatment III (Control).

\begin{tabular}{lcccccccc}
\hline Formigueiro & \multicolumn{2}{c}{ F31 (HI) } & \multicolumn{2}{c}{ F32 $(\mathrm{HI})$} & \multicolumn{2}{c}{ F09 $(\mathrm{CR})$} & \multicolumn{2}{c}{ F11 (CR) } \\
\hline Data & Externa & Interna & Externa & Interna & Externa & Interna & Externa & Interna \\
\hline $09 / 12 / 2012$ & 41,8 & 25,9 & 32,8 & 21,8 & & & & \\
$09 / 12 / 2012$ & 29,7 & 27,3 & 31,6 & 25,6 & & & & \\
$10 / 12 / 2012$ & 35,1 & 24,4 & 34,3 & 22,6 & & & & \\
$28 / 12 / 2012$ & 25,4 & 23,9 & 27,3 & 20,3 & & & & \\
$12 / 01 / 2013$ & 39,3 & 24,1 & 37,2 & 20,9 & 40,3 & 24,8 & 32,6 & 22,1 \\
\hline Média geral & 34,260 & 25,120 & 32,640 & 22,240 & 40,300 & 24,800 & 32,600 & 22,100 \\
\hline
\end{tabular}

(CR): A. crassispinus. (HI): A. hispidus.

Em relação à temperatura interna ideal para o crescimento do fungo, esta constatação não foi possível de ser verificada, uma vez que os formigueiros F13, F30, F27 e F14 apresentaram temperatura interna superior a $20^{\circ} \mathrm{C}$, mesmo após as formigas terem abandonado a colônia, conforme as observações de campo. Uma possível causa para esta divergência de observação (temperatura interna superior a $20^{\circ} \mathrm{C}$ com ausência de formigas), em relação aos dois estudos citados, pode ser devido ao estudo de Powell e Stradling (1986) ter sido realizado em laboratório, sob condições controladas de temperatura e umidade relativa do ar, e o estudo de Bollazzi e Roces (2010) ter sido conduzido em campo em uma região mais fria (sul do Uruguai) em relação à região em que foi realizado o presente trabalho. Outra possível causa para esta temperatura interna ser superior a $20^{\circ} \mathrm{C}$, mesmo com a ausência de formigas, pode ser devido ao fato de as temperaturas externas terem sido muito elevadas durante o período de realização do experimento, conforme pode ser observado nas tabelas 3,4 e 5 , em que na maioria dos casos a temperatura externa média foi superior a $31{ }^{\circ} \mathrm{C}$, sendo que em alguns casos houve picos de calor extremo.

Não havendo diferença significativa entre as temperaturas internas dos três tratamentos realizados, procurou-se verificar se havia correlação entre a área dos formigueiros estudados e a temperatura interna das colônias, nos momentos "com" e "sem" formigas.

As correlações para as colônias no momento em que havia formigas, entre suas respectivas áreas e temperaturas internas, indicaram que não houve correlação entre elas; e as correlações para as colônias no momento em que não havia formigas, entre suas respectivas áreas e temperaturas internas, indicaram que houve correlação entre elas, porém esta correlação foi muito fraca, conforme tabela 6 .

Tabela 6. Correlação entre a média das temperaturas internas com e sem formigas $\mathrm{x}$ área do formigueiro. Table 6. Correlation between the average internal temperatures with and without ants $\mathrm{x}$ nest area.

\begin{tabular}{|c|c|c|c|c|}
\hline \multirow[b]{2}{*}{ Formigueiro } & \multicolumn{2}{|c|}{ Com formigas } & \multicolumn{2}{|c|}{ Sem formigas } \\
\hline & $\bar{x}$ TI $^{\circ} \mathbf{C}$ & Área m² & $\bar{x}$ TI $^{\circ} \mathbf{C}$ & Área $\mathbf{m}^{2}$ \\
\hline F23 (CR) & 24,008 & 0,7200 & 21,160 & 0,7200 \\
\hline F13 (CR) & 22,850 & 0,4818 & 23,287 & 0,4818 \\
\hline F02 (CR) & 21,500 & 0,1720 & 22,508 & 0,1720 \\
\hline F30 (CR) & 28,340 & 0,3000 & 27,975 & 0,3000 \\
\hline F27 (HI) & 27,000 & 0,2808 & 23,075 & 0,2808 \\
\hline F14 (HI) & 26,775 & 0,0300 & 22,800 & 0,0300 \\
\hline F21 (CR) & 23,900 & 0,1400 & 19,500 & 0,1400 \\
\hline $\mathrm{F} 22(\mathrm{CR})$ & 22,650 & 0,0300 & 21,450 & 0,0300 \\
\hline & Temp. & Área & Temp. & Área \\
\hline Temp. & 1 & & 1 & \\
\hline Área & $-0,039129371$ & 1 & 0,074771904 & 1 \\
\hline
\end{tabular}

$\overline{\bar{x}} \mathrm{TI}{ }^{\circ} \mathrm{C}$ : média das temperaturas internas em ${ }^{\circ} \mathrm{C}$. (CR): A. crassispinus. (HI): A. hispidus. 
Sendo assim, é possível concluir que as áreas dos formigueiros não influenciaram nas temperaturas internas dos mesmos, tanto nos momentos em que havia formigas, quanto nos momentos em que não havia formigas nas colônias.

\section{CONCLUSÕES}

As análises realizadas permitem concluir que:

- A extração do óleo essencial das folhas de D. angustifolia em equipamento industrial demonstra ser viável, sendo possível obter óleo essencial de folhas frescas e secas.

- O percentual de rendimento da extração do óleo essencial das folhas secas é maior quando comparado ao percentual obtido com a extração realizada com as folhas frescas.

- Alguns dos principais monoterpenos relacionados à baixa palatabilidade das formigas às acículas maduras de $P$. taeda são encontrados no óleo essencial de D. angustifolia.

- O óleo essencial de $D$. angustifolia demonstra possuir função antagônica às formigas nos dois tratamentos realizados.

- A concentração de $100 \%$ de óleo essencial desencadeia um comportamento anormal das formigas nas primeiras avaliações após a sua aplicação.

- A utilização da temperatura interna das colônias não mostra ser um bom parâmetro de avaliação para verificação da ação do óleo quando comparado com a literatura citada.

- A aplicação do óleo essencial de D. angustifolia altera o comportamento das formigas e demonstra possuir potencial para investigação no controle alternativo de formigas cortadeiras do gênero Acromyrmex Mayr, 1865.

\section{AGRADECIMENTOS}

Este trabalho representa parte da dissertação de Mestrado do primeiro autor, Programa de PósGraduação em Engenharia Ambiental da Universidade Regional de Blumenau (FURB). Agradecemos à Celulose Irani, pela cessão da área de pesquisa; ao FUMDES (Fundo de Apoio à Manutenção e ao Desenvolvimento da Educação Superior no Estado de Santa Catarina), pelo apoio financeiro.

\section{REFERÊNCIAS}

ADAMS, R. P. Identification of essential oil components by gas chromatography, mass spectroscopy. 4th. ed. Carol Stream, Illinois, USA: Allured, 2007.

BOARETTO, M. A. C.; FORTI, L. C. Perspectivas no controle de formigas cortadeiras. Série Técnica IPEF, São Paulo, v. 11, n. 30, p. 31 - 46, 1997.

BOLLAZZI, M.; ROCES, F. The thermoregulatory function of thatched nests in the South American grass-cutting ant, Acromyrmex heyeri. Journal of Insect Science, v. 10, n. 137, p. 1 - 17, 2010.

BUENO, O. C. Plantas inseticidas no controle de formigas cortadeiras. Agroecologia-hoje, Botucatu, SP, ano 4, n. 28, p. 20 - 22, 2005, 2005.

CAMARGO, R. S.; FORTI, L. F.; LOPES, J. F. S.; NAGAMOTO, N. S. Studies on Leaf-Cutting ants, Acromyrmex spp. (Formicidae, Attini): Behavior, reproduction and control. Recent Research Developments in Entomology, v. 5, p. 1 - 21, 2006.

CANTARElli, E. B.; COSTA, E. C.; MOREL, A.; PEZZUTTI, R. Avaliação de óleos essências de acículas de Pinus taeda quanto à preferência no corte por formigas. Anais do Simpósio de Mirmecologia, 16., Florianópolis, SC, p. 477 - 479, 2003.

CHERRETT, J. M. The economic importance and control of leafcutting ants. In: VINSON, S. B. (Ed.). Economic impact and control of social insects. New York: Praeger, 1986. p. 165 - 192.

DELLA LUCIA, T. M. C. Formigas cortadeiras: da Bioecologia ao Manejo. Viçosa, MG: Editora da UFV, 2011. 
DERITA, M. G.; LEIVA, M. L.; ZACHINO, S. A. Influence of plant part, season of collection and content of the main active constituent, on the antifungal properties of Polygonum acuminatum Kunth. Journal of Ethnopharmacology, New York, USA, v. 124, p. 377 - 383, 2009.

FERNANDÉZ-MARÍN, H.; ZIMMERMAN, J. K.; WCISLO, W. T. Ecological traits and evolutionary sequence of nest establishment in fungus-growing ants (Hymenoptera, Formicidae, Attini). Biological Journal of the Linnean Society, v. 81, p. 39 - 48, 2004.

FLORIANI, S. C. Atividade antimicrobiana do extrato hexânico de Drimys angustifolia. 2010. 34 f. Trabalho de Conclusão de Curso (Curso de Farmácia), Universidade Regional de Blumenau (FURB), Blumenau, SC, 2010.

FOREST STEWARDShIP COUNCIL (FSC). Fsc Pesticides Policy Guidance Addendum: List of Approved Derogations for use of 'Highly Hazardous' Pesticides - Fsc-gui-30-001a V1-0 En (updated February 2012). Disponível em: 〈http://ic.fsc.org/guidance.335.htm〉. Acesso em: 13 out. 2012.

GAVIRIA, M.; QUIJANO, C.; PINO, J.; MADRIÑÁN, S. Chemical Composition and Antibacterial Activity of the Essential Oil of Drimys granadensis L.f. Leaves from Colombia. Chemistry \& Biodiversity, Zürich, Switzerland, v. 8, p. 532 - 539, 2011.

GOBBO-NETO, L.; LOPES, N. P. Plantas medicinais: fatores de influência no conteúdo de metabólitos secundários. Química Nova, São Paulo, v. 30, n. 2, p. 374 - 381, 2007.

HÖLLDOBLER, B.; WILSON, E. O. The ants. Cambridge: Harvard University Press, 1990.

JACCOUD, D'A. de B. Formigas cortadeiras: princípios de manejo integrado de áreas infestadas. Instituto Brasileiro do Meio Ambiente e dos Recursos Naturais Renováveis. Série Meio Ambiente em debate, ISSN 1413-2583; 34. Brasília: Ed. IBAMA, 2000.

LIMBERGER, R. P.; SCOPEL, M.; SOBRAL, M.; HENRIQUES, A. T. Comparative analysis of volatiles from Drimys brasiliensis Miers and D. angustifolia Miers (Winteraceae) from Southern Brazil. Biochemical Systematics and Ecology, v. 35, n. 3, p. 130 - 137, 2007.

LOPES, G. A. Política de uso de agroquímicos adotada pelo FSC (Revista Opiniões, dez. 2008-fev. 2009). Disponível em: <http://revistaonline.revistaopinioes.com.br/revistas/revistas/32/\#page/39>. Acesso em: 13 out. 2012.

MALHEIROS, A. Estudos químicos farmacológicos e alelopáticos das espécies Drimys angustifolia e Drimys brasiliensis (WINTERACEAE). 2001. 184 f. Tese (Doutorado em Química), Universidade Federal de Santa Catarina (UFSC), Florianópolis, SC, 2001.

MARICONI, F. A. M. Inseticidas e seu emprego no combate às pragas: vol. 1 - Defensivos. 5. ed. São Paulo: Nobel, 1981.

MENEGHETTI, E. K. Extração, caracterização e avaliação antibacteriana do óleo essencial de Drimys angustifolia Miers. 2010. 77 f. Trabalho de Conclusão de Curso (Química), Universidade Regional de Blumenau (FURB), Blumenau, SC, 2010.

NICKELE, M. A. Dinâmica populacional e ecologia do forrageamento de Acromyrmex Mayr, 1865 (Hymenoptera: Formicidae). 2013. 156 f. Tese (Doutorado em Ciências Biológicas), Universidade Federal do Paraná (UFPR), Curitiba, PR, 2013.

PEREIRA, L. G. B. Estratégias de controle de formigas cortadeiras: dossiê técnico. Belo Horizonte: CETEC, 2007. Disponível em: 〈http://sbrt.ibict.br/dossie-tecnico/downloadsDT/OTY=>. Acesso em: 14 out. 2012.

PIZZAMIGLIO, M. A. Ecologia das interações inseto/planta. In: PANIZZI, A. R.; PARRA, J. R. (Ed.). Ecologia nutricional de insetos e suas implicações no manejo de pragas. São Paulo: Manole, 1991. cap. 4, p. $101-129$.

POWELL, R. J.; STRADLING, D. J. Factors influencing the growth of Attamyces bromatificus, a symbiont of Attine ants. Transactions of the British Mycological Society, v. 87, n. 2, p. 205 - 213, 1986. 
RIBEIRO, V. L. S.; ROLIM, V.; BORDIGNON, S.; HENRIQUES, A. T.; DORNELES, G. G.; LIMBERGER, R. P.; POSER, G. Chemical composition and larvicidal properties of the essential oils from Drimys brasiliensis Miers (Winteraceae) on the cattle tick Rhipicephalus (Boophilus) microplus and the brown dog tick Rhipicephalus sanguineus. Parasitology Research, Berlin, v. 102, n. 3, p. 531 - 535, 2008.

SILVA, L.; ONIKI, G. H.; AGRIPINO, D. G.; MORENO, P. R. H.; YOUNG, M. C. M.; MAYWORM, M. A. S.; LADEIRA, A. M. Biciclogermacreno, resveratrol e atividade antifúngica em extratos de folhas de Cissus verticillata (L.) Nicolson \& Jarvis (Vitaceae). Revista Brasileira de Farmacognosia, João Pessoa, v. 17, n. 3, p. 361 - 367, 2007.

SOUSA, N. J. Avaliação do uso de três tipos de porta-iscas no controle de formigas cortadeiras, em áreas preparadas para a implantação de povoamentos de Pinus taeda L. 1996. 72 f. Dissertação (Mestrado em Engenharia Florestal), Universidade Federal do Paraná (UFPR), Curitiba, PR, 1996.

UKAN, D. Avaliação qualitativa e quantitativa de micro-porta-iscas para o controle de formigas cortadeiras, em plantios de Eucalyptus urograndis submetidos a diferentes cronogramas silviculturais. 2008. 78 f. Dissertação (Mestrado em Ciências Florestais), Universidade Federal do Paraná (UFPR), Curitiba, PR, 2008.

VASCONCELOS, H. L.; CHERRETT, J. M. Leaf-cutting ants and early forest regeneration in central Amazonia: effects of herbivory on tree seedling establishment. Journal of Tropical Ecology, v. 13, n. 3, p. 357 - 370, 1997.

VIEIRA, P. C.; FERNANDES, J. B.; ANDREI, C. C. Plantas inseticidas. In: SIMÕES, C. M. O. et al. (Org.). Farmacognosia: da planta ao medicamento. 6 ed. $1^{\text {a }}$ reimpr. Porto Alegre/Florianópolis: Editora da UFRGS/Editora da UFSC, 2010. cap. 35, p. 903 - 918.

ZANETTI, R.; CARVAlHO, G. A.; SANTOS, A.; SOUZA-SILVA, A.; GODOY, M. S. Manejo Integrado de Formigas Cortadeiras. Lavras, MG: UFLA, 2002. 